\title{
Endoscopic Thyroidectomy: A Literature Review and Update
}

\author{
Kai-Pun Wong · Brian Hung-Hin Lang
}

Published online: 19 December 2012

(C) Springer Science + Business Media New York 2012

\begin{abstract}
Since the first report of endoscopic subtotal parathyroidectomy in 1996, a variety of endoscopic surgical approaches has been reported. These endoscopic approaches include the minimally-invasive video-assisted thyroidectomy (MIVAT), the endoscopic lateral approach, the lateral mini-incision approach, the anterior/chest (hybrid) approach, the transaxillary approach, the axillobreast approach, the post-auricular and axillary approach, and other novel experimental approaches. Some of these approaches could be done with the assistance of the da Vinci robot (i.e. robotic-assisted thyroidectomy). For simplification, these approaches could be categorized into the cervical/direct approach and the extra-cervical/indirect approach. Each technique or approach has its own benefits and weaknesses. Currently, there is no preferred approach in the literature and the choice seems to be determined by the surgeon's own experience and the patient's preference. In our experience, the transaxillary approach was a technically more challenging procedure and was associated with longer hospital stay, longer operating time, more immediate pain, and increased overall RLN injury and morbidity than MIVAT. The 6-month scar appearance and patient satisfaction were similar between the two procedures.
\end{abstract}

K.-P. Wong

Division of Endocrine Surgery, Department of Surgery,

The University of Hong Kong, Queen Mary Hospital,

Hong Kong, Hong Kong

B. H.-H. Lang ( $\square)$

Department of Surgery, The University of Hong Kong, Queen Mary Hospital, Pokfulam Road, Hong Kong, Hong Kong e-mail: blang@hkucc.hku.hk
Keywords Thyroidectomy - Endoscopic thyroidectomy · Minimally invasive thyroidectomy $\cdot$ Scarless $\cdot$ Literature review $\cdot$ MIVAT $\cdot$ Robotic-assisted thyroidectomy

\section{Introduction}

Thyroidectomy remains one of the most commonly performed surgical procedures. With increasing demand for better safety and surgical outcomes of elective surgical procedures from the community, many thyroid surgeons have adopted a number of new technologies such as intraoperative neuro-monitoring of recurrent laryngeal nerve (RLN), post-operative parathyroid hormone assay and alternative energy device such as ultrasonic shears or bipolar coagulation. Other examples of new surgical technology include endoscopic instruments and the highdensity telescope which have allowed surgeons to make a smaller incision and be minimally invasive. Any procedure which involves using the endoscope is often collectively called "endoscopic thyroidectomy".

The subject of "endoscopic thyroidectomy" has generated immense interest among thyroid surgeons. Since the first report in endoscopic parathyroidectomy reported by Gagner et al. in 1996 [1], various minimal invasive approaches have been described in the literature. They could be generally classified into direct/cervical and indirect/extra-cervical approaches depended on the location of the incision [2]. For the direct/cervical approach, small incision(s) are made in the neck area and the thyroid gland is exposed directly similar to the conventional thyroidectomy but with endoscopic instruments. It may be regarded as truly minimal invasive because incisions are generally smaller than the conventional approach and the amount of surgical dissection is generally less. Figure 1 shows the 
amount of tissue dissection needed with each approach. Two widely reported examples include the minimally invasive video-assisted thyroidectomy (MIVAT) and the minimally invasive lateral approach. On the other hand, the indirect/extra-cervical approach involves having incisions outside the neck area or extra-cervical region, e.g., axillary, peri-areolar or post-auricular region. The main advantage of this approach is that there is no visible scar in the neck, or "scarless" in the neck. However, it is often criticized for being maximally invasive because extensive subcutaneous dissection is often required with this approach [3]. Furthermore, it is technically more demanding and might be associated with a higher morbidity rate. Perhaps, because of the technical difficulties, most of the large reported series came from specialized centers with interest in thyroid surgery. Therefore, its application to the wider surgical community remains questionable. More recently, the use of the da Vinci Robotic system has been reported in order to overcome some of these technical issues. This review served as an update describing various endoscopic thyroidectomy approaches and the evidence for and against each approach based on the current literature.

\section{Cervical/Direct Endoscopic Approaches}

\section{MIVAT}

The MIVAT was first described by a group of surgeons from Pisa, Italy, in 1998 [4]. It was quickly adopted by surgeons worldwide because it was truly minimally invasive and the use of the endoscope gave the surgeons a magnified view of the operative field. MIVAT is often regarded as a hybrid procedure as opposed to other endoscopic procedures because it requires both open and laparoscopic surgical skills. Similar to the traditional thyroidectomy, the patient is often put under a general anaesthesia, although regional anaesthesia by bilateral deep cervical plexus block is possible. A $1.5-\mathrm{cm}$ midline incision is then made about $2 \mathrm{~cm}$ above the sternal notch. The midline is incised longitudinally for $3-4 \mathrm{~cm}$ to separate the strap muscle. The strap muscle is then separated from the thyroid with a blunt dissection. The operative field is developed and maintained by an external retractor held by an assistant. After that, the operation is conducted in an endoscopic/video-assisted manner. A 5-mm $30^{\circ}$ telescope is inserted with the external branch of superior laryngeal nerve identified and preserved with the help of the optical magnification of the telescope. The superior lobe vessel is then either clipped or divided by ultrasonic shears. The superior lobe is gradually pulled and delivered through the wound. Thereafter, the rest of the procedure is performed not dissimilar to the conventional thyroidectomy. The contralateral lobe would be excised and delivered in similar manner. No drain is needed and skin is closed with subcuticular stitches and sealant.

This technique is associated with excellent cosmetic and surgical outcomes [5, 6]. However, only $10-15 \%$ of patients with a small goiter would be suitable. Only patients with a solitary thyroid nodule $<35 \mathrm{~mm}$ and/or thyroid volume $<25 \mathrm{ml}$ are considered suitable for MIVAT. Besides size, redone surgery, previous neck irradiation and locally invasive carcinoma are also considered absolute contraindications [7]. The presence of the hypervascular gland, e.g,. Graves' disease or thyroiditis, were initially thought to be contraindications for MIVAT. However, in the latest review of 1,946 patients by the same group of surgeons, $17.9 \%$ of patients with benign disease on final pathology had thyroiditis while $30.9 \%$ of patients with malignancy had unexpected thyroiditis. Therefore, the presence of thyroiditis is no longer considered a contraindication in MIVAT [8]. With more experience, the application of MIVAT has been extended to pediatric patients as well as patients requiring lateral functional neck dissection for lymph node metastases $[9,10]$.

Since the first report on MIVAT, numerous comparative studies have evaluated the outcome of MIVAT with the conventional thyroidectomy [11]. A recent meta-analysis did not find significant differences in post-operative hypocalcemia and RLN palsy rates, and the MIVAT generally took longer to complete (odds ratio $(\mathrm{OR})=1.681$, $95 \% \mathrm{CI}=0.600-2.762, p=0.023]$ [12••]. However,
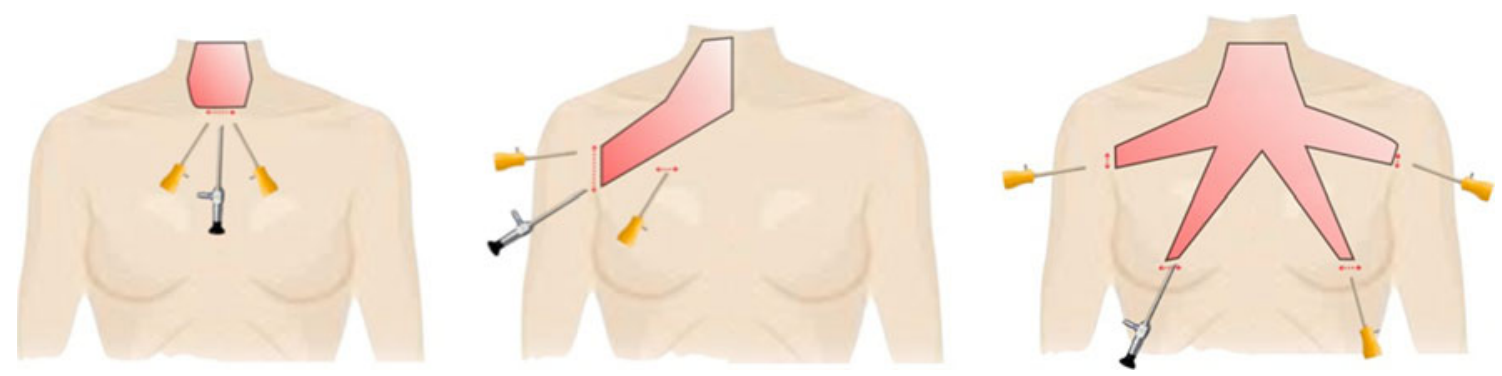

Fig. 1 The areas of dissection of different endoscopic thyroidectomy. From left to right, minimally invasive video-assisted thyroidectomy, transaxillary thyroidectomy, and endoscopic thyroidectomy by bilateral axillo-breast approach 
MIVAT was associated with a lower pain score at $24 \mathrm{~h}$ post-operative $(\mathrm{OR}=-4.496,95 \% \mathrm{CI}=-7.146$ to $-2.045, p=0.0004)$ and better reported cosmesis score $(\mathrm{OR}=3.669,95 \% \mathrm{CI}=0.636-60.702, p=0.178)[12 \bullet \bullet$.

Common indications for MIVAT include indeterminate and low- to intermediate-risk papillary carcinoma. MIVAT appeared to have a comparable oncological outcome as conventional thyroidectomy [14]. The thyroglobulin levels, thyrotrophin-stimulating hormone and percentage of radiouptake were not different in early operations and long term follow-up [13, 14]. There was no significant difference in cure rate after a median follow-up of 5 years in these groups of low-risk PTC patient [14].

\section{Endoscopic Lateral Approach}

Unlikely the conventional thyroidectomy and MIVAT, the initial incision is made over the sternocleidomastoid muscle (SCM). The thyroid gland is approached laterally through splitting of strap muscle and SCM. Henry et al. [15] first reported their technique on the endoscopic lateral approach in 1999. One 10-mm and two 3-mm ports were inserted along the SCM. Operating space is maintained with low pressure $\mathrm{CO}_{2}$ insufflation. Vital structures, like the parathyroid gland, RLN and the external branch of the superior laryngeal nerve could be readily identified and preserved. With the help of needloscopic instruments and magnification, individual vessels can be controlled and the thyroid completely dissected free. The specimen is normally retrieved through a $12-\mathrm{mm}$ incision.

However, one of the disadvantages with this approach is that only unilateral pathology can be resected (i.e. hemithyroidectomy) because the incision is only placed on one side of the neck. If the contralateral side needs to be explored at the same time, a collar incision (i.e. extension of the incision) would be required. However, only $5 \%$ will require a conversion if cases are properly selected [2]. On the other hand, strict criteria meant that only $5 \%$ of the workload was eligible for this approach [2].

\section{Lateral Mini-incision Technique}

Similar to the endoscopic lateral approach, the thyroid gland is approached by entering the plane between the SCM and the strap muscles. Instead of using endoscopic instruments, it is done in an open fashion. It was first described by Delbridge et al. [16]. A small $(2.5 \mathrm{~cm})$ lateral incision is made over the nodule and the subplatysmal flap is raised to allow skin incision to be move around the neck and relevant area of dissection. The anterior border of the SCM is incised to expose the lateral margin of the strap muscle. The strap muscle is retracted medially and the
SCM is retracted laterally to expose the lateral part of the thyroid gland. The middle thyroid vein is first divided and then the isthmus is mobilized and transected to allow maximal mobilization. The skin incision is then retracted cranially to expose the upper pole vessels which are then divided. The lower pole is mobilized with careful capsular dissection with preservation of the inferior parathyroid gland. The thyroid gland is then delivered through the skin incision. The rest of the procedure is similar to conventional thyroidectomy. With careful capsular dissection, the superior parathyroid gland and RLN can be dissected away from thyroid gland and preserved.

Compared to conventional hemithyroidectomy, Sywak et al. reported a single arm-blinded randomized trial. They found that the mini-incision approach took an extra 10 min but was associated with a lower pain score on the 1st postoperative day ( $2.67 \mathrm{vs} .3 .43, p=0.032$ ) and 10 th day (1.5 vs. $1.8, p=0.36)$, greater cosmetic satisfaction score (6.3 vs. $5.0, p=0.002)$ and a smaller wound $(2.6$ vs. $5.4 \mathrm{~cm}$, $p<0.001$ ) [17]. However, owing to the fact that the incision is placed on one side of the neck only, it is limited to hemithyroidectomy. Nevertheless, it is relatively easier to learn than other types of endoscopic operation [18, 19].

\section{Extra-Cervical/Indirect Approaches}

\section{Anterior Chest/Breast Approach}

In 1998, Shimizu et al. reported their experience of approaching the thyroid gland via the infra-clavicular incisions. It is termed video-assisted neck surgery [20]. The operation was aimed to be "scarless" over the neck. However, due to incomplete covering of the infra-clavicular scar by clothing and a high chance of scar hypertrophic change, Ohgami et al. [21] modified the incision and placed it at the upper circum-areolar areas in 2000.

The initial incision is made at infra-clavicular or bilateral upper circum-areolar areas. The skin flap is raised by blunt dissection of subcutaneous tissue and the sub-platysmal space. The operating space is maintained by a skinlifting device or $\mathrm{CO}_{2}$ insufflation. An additional port is inserted at the infra-clavicular region. The strap muscle is divided longitudinally to expose the thyroid gland. The rest of the procedure is similar to open thyroidectomy, with the dissection initiated from the inferior lobe and proceeding postero-laterally and then superiorly under the aim of endoscopic instruments. Individual vessels are controlled with ultrasonic shears and the whole course of the RLN is identified and preserved. Despite good covering of the scars, some patients do not want any dissection around the nipple areolar region as the presence of a breast implant is a concern [22]. 
Trans-Axillary Approach

Trans-axillary approach offers good cosmesis as the axillary wound can be covered by the patient's own clothes. It also avoids unnecessary dissection around the areolar region. It was first described by Ikeda et al. in 2000 [23]. To our knowledge, over 1,500 patients have undergone this approach [24-34]. The patient is put under general anesthesia and lies in a supine position. The neck is slightly extended and the ipsilateral arm is raised and fixed at the shortest distance between the axilla and anterior neck. A 4- to 6-cm vertical incision is made along the outer border of the pectoris major. The skin flap is raised superficial to the pectoralis fascia and toward the anterior neck. The avascular plan between the sternal and clavicular head of SCM is developed. The anterior part of the thyroid is dissected free from strap muscles and the skin flap is raised with a skinlifting device.

A 10-mm and a 5-mm trocar are placed on either end of the axillary wound. Another 5-mm trocar is placed in the chest. The inferior pole of the thyroid is carefully dissected to isolate the RLN and parathyroid glands. Vessels are divided between clips or by ultrasonic shears. The thyroid is then retracted medially. Berry's ligament is dissected and divided. For hemithyroidectomy, the isthmus is transected using ultrasonic shears, while the medial approach for contralateral thyroid would be needed if bilateral resection is indicated. The specimen is retrieved through the axillary wound and the operating field is irrigated. A drain is placed before wound closure. This approach avoids any scar over the neck. The distance between the incision and the thyroid is short and therefore less subcutaneous dissection is needed. However, contralateral dissection is difficult and a collision of instruments is common due to the limited working space. Figure 2 shows pictures of a patient who underwent transaxillary thyroidectomy after 3 months.

The largest series was reported by Kang et al. in 2009. A total of 581 patients including 410 with cancer underwent the gasless endoscopic thyroidectomy [27]. The complication rates were not high with $3.2 \%$ of patients having transient hypocalcemia, $1.5 \%$ having transient hoarseness, and $0.2 \%$ having permanent RLN palsy. Compared to the conventional approach, this approach took a longer time [28]. Patients also had more pain but were more satisfied [35]. Figure 3 shows the endoscopic view of transaxillary thyroidectomy. On the other hand, some studies suggested that the trans-axillary approach might be associated with a higher rate of transient hypocalcemia and transient RLN palsy $[36,37]$. In a patient with a low-risk papillary thyroid microcarcinoma, Jeong et al. reported that trans-axillary thyroidectomy with prophylactic central neck dissection was feasible. Oncologically, though smaller numbers of the lymph node were retrieved than that of the conventional approach (5.05 vs. $5.96, p=0.007)$, none of 275 patients who underwent trans-axillary approach had $\mathrm{Tg}>1 \mathrm{ng} / \mathrm{ml}$. In the conventional group, 6 of $224 \mathrm{had} \mathrm{Tg}>1 \mathrm{ng} / \mathrm{ml}$. However, there might have been some selective bias with the results as high-risk patients were likely undergoing the conventional approach [36]. With application of the da Vinci robotic system and maturation of skills, the discussion on the endoscopic approach on central and lateral neck dissection has largely shifted to the robotic approach (see later) $[38 \bullet \bullet, 39,40]$.

Further advances in trans-axillary approach have been proposed to optimize or maximize the cosmetic outcome of the wound. The presence of an anterior chest incision was associated with hypertrophic change or even keloid, especially in Asian patients. Surgeons from Korea proposed lowering the incisions and placing them at the peri-areolar site to decrease the "visibility" of the scar, namely the unilateral axillo-breast approach [41]. The central neck compartment and a tumor nodule $\geq 4 \mathrm{~cm}$ could be tackled by this approach [41, 42]. On the other hand, a singleincision in the axilla was shown to be feasible $[43,44]$.

\section{Axillo-Breast (Hybrid) Approach}

In the anterior approach and the trans-axillary approach, the narrow endoscopic view and limited angulation of instruction are the major technical challenges for surgeons. To overcome these limitations, Shimazu et al. [45] in Japan first described using both axillary and breast incisions and the so-called axillo-bilateral-breast approach. The patient is under general anesthesia and the arms are abducted. An ipsilateral circumareolar incision is made. The subcutaneous and sub-platysmal working space is developed with blunt dissection similar to the anterior chest/breast approach. The working space is extended to the level of the thyroid cartilage superiorly and the medial edge of SCM bilaterally. The working space is maintained with low pressure $\mathrm{CO}_{2}$ insufflation. Additional ports are inserted through the ipsilateral axilla and the contralateral circum-areolar incision. The rest of the procedure is similar to the anterior chest/breast approach. Through endoscopic instruments inserted into the axillary port, a wider triangulation of the facilitates the dissection and mobilization of the thyroid gland. The resected thyroid gland is retrieved through the circum-areolar wound with a plastic bag.

Choe et al. added another incision to the contralateral axilla and this is now known as the bilateral axillo-breast approach (BABA) [46]. From a large series of 512 patients with thyroidectomy via BABA, Choi et al. [47••] reported a low rate of permanent hypocalcemia $(4.2 \%)$ and RLN palsy $(1.7 \%)$. However, the transient hypocalcemia rate $(31.1 \%)$ and the proportion of transient RLN palsy (20.1\%) was relatively high compared to other reported series $(\sim 4 \%)$ [46]. However, because the technique 

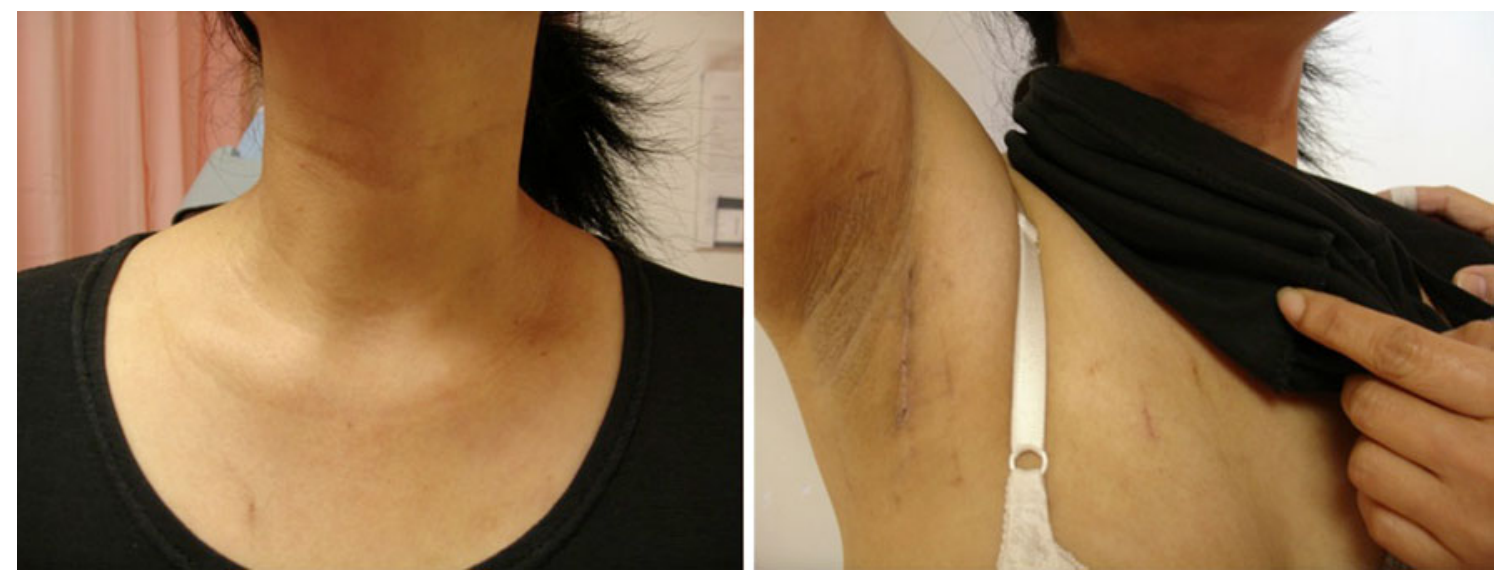

Fig. 2 A patient who underwent transaxillary thyroidectomy 3 months after the operation

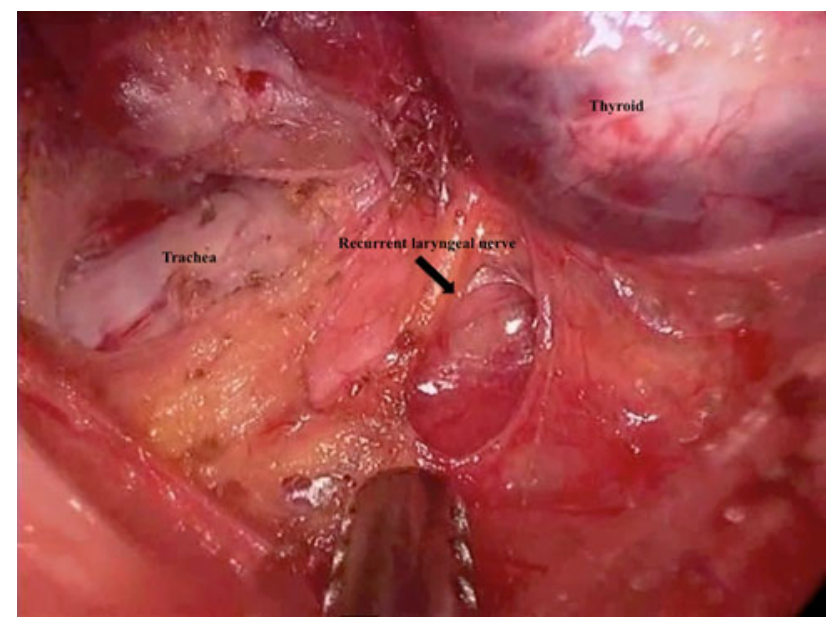

Fig. 3 Endoscopic lateral view of thyroid gland during transaxillary thyroidectomy. Thyroid gland was retracted medially and the recurrent laryngeal nerve was dissected clearly

involves extensive subcutaneous flap dissection, it is often criticized for being "maximally" invasive [48]. It results in upper chest discomfort, pain and fibrosis of the skin flap and prolongs paraesthesia for up to 12-18 months [49]. Unlike the trans-axillary approach, the experience of BABA is reported mainly in Asian countries. We think that this might be related to better acceptance of the peri-areolar incision and extensive dissection over subcutaneous tissue over the breast. Furthermore, the larger-sized breasts commonly seen in the Caucasian population makes BABA more difficult.

\section{Post Auricular and Axillary Approach}

To avoid dissection around the peri-areolar region and maintain triangulation of manipulation, Lee et al. [50] reported this approach by making the incision at the bilateral axillary and post-auricular region. The operation starts with an infusion of a diluted adrenaline solution to the subcutaneous and sub-platysmal space of the anterior chest and neck. After making a 12-mm incision at the ipsilateral axilla, the subcutaneous space is created with blunt dissection. A 12-mm trocar is inserted into the axillary wound and the operative space is inflated with low pressure $\mathrm{CO}_{2}$. Another port is inserted into the contralateral axilla and two 5-mm trocars are inserted through the bilateral post-auricular incision. A midline incision is made and the strap muscle is split and retracted laterally by the endoscopic instrument through post-auricular ports. The thyroid is dissected and excised similar to the conventional anterior approach. It is a technically challenging operation. Branches of the facial nerve were also susceptible to traction injury. Even though it avoids the peri-areolar dissection, this technique has not been popular.

\section{Other Novel Approaches}

Other novel endoscopic approaches were mostly based on cadavers. These techniques included the retro-auricular video-assisted gasless thyroidectomy [51], and the totally trans-oral video-assisted thyroidectomy (TOVAT) under gas insufflations [52]. In cadaver studies, it is feasible to excise the thyroid gland through an incision in the floor of the mouth under gas insufflation. Two cases of trans-oral parathyroidectomy in 2 patients with primary hyperparathyroidism have been reported [53]. This approach seems to be technically feasible but is heavily criticized on its safety. The working space is very limited and potential infection through a relatively contaminated incision is a major concern $[54,55]$.

\section{Robotic-Assisted Thyroidectomy}

Since the first report of robotic trans-axillary thyroidectomy in 2009, robotic thyroidectomy has been widely 
performed worldwide [56-59]. Theoretically, it overcomes many of the technical challenges associated with transaxillary thyroidectomy because the robot can provide a threedimensional magnified view, seven degree of freedom and 90 articulation and can filter any hand tremors [56]. In a multi-center study with 2,014 patients, Lee et al. [60] showed that robotic thyroidectomy had a minimal major complication rate of about $1 \%$ and superior surgical ergonomic benefits for surgeons. On questioning, seven operating surgeons performing robotic thyroidectomy had a low rate of neck pain and/or back pain compared to preforming open or endoscopic thyroidectomy [60]. Like endoscopic thyroidectomy, single-incision transaxillary robotic-assisted thyroidectomy or robotic thyroidectomy using the BABA approach have been reported as feasible and safe surgical approach options $[61 \bullet \bullet, 62]$.

We reported our initial experience of 7 robotic thyroidectomies and compared their outcomes with that of endoscopic thyroidectomy. We found the former had similar complication rates but took longer to perform. However, identification of contralateral RLN was easier (100 vs. $42.9 \%, p=0.070$ ) [59]. In contrast to our result, operation time was generally shorter than in other groups of surgeons [57, 63••]. This was probably related to the early phase of the learning curve [64]. Robotic transaxillary thyroidectomy appeared to have a shorter learning curve than endoscopic thyroidectomy (35-40 vs. $55-60$ cases) [65••]. In terms of post-operative complication, no significant difference has been reported despite one comparative study suggesting a higher rate of transient hypocalcemia [63・0]. The author hypothesized that this could be due to more complete removal of the peri-thyroidal fascia and tissue leading to thermal damage or transient ischemia of the parathyroid gland.

Oncologically, incorporation of prophylactic central neck dissection into endoscopic or robotic thyroidectomy is advocated. With the help of the robotic system, higher numbers of the central neck lymph node could be retrieved [57, 63••]. In a large Korean series of 1,150 patients with papillary thyroid microcarcinoma, after 1 year of followup, post-operative serum thyroglobulin was comparably low in both endoscopic and robotic-assisted thyroidectomy. No abnormal uptake after radioactive ablation or recurrence on neck ultrasonography was noted [63・•]. This signified that complete, oncologically safe, surgical removal of the thyroid gland is feasible by both techniques.

One of the major and most important limitations with any robotic procedure is the cost. The cost is not just limited to the initial installment of the da Vinci Robotic system, but also includes the expensive consumables, ongoing maintenance, and training of staff. The average operation cost is nearly eight times more than the conventional approach (US\$ 6,655 vs. 829, $p<0.01$ ) $[26,66]$. Therefore, routine use of the robotic-assisted approach might not be justified in the economic sense. Further studies on the cost-effectiveness of robotic thyroidectomy are needed.

In addition to the trans-axillary and axillo-breast approaches, an innovative remote approach, namely the robotic facelift thyroidectomy, has recently been reported [67]. The patient lies in a supine position with the head slightly rotated away from the side of pathology. The incision is then made along the post-auricular crease extending into the occipital hairline. The SCM is dissected along its anterior border. The greater auricular nerve and external jugular vein are identified and retracted anteriorly. The avascular space between the SCM and the strap muscles is developed and the working space is maintained by an external retractor. The robotic system is docked. The dissection of the thyroid gland begins in the superior pole and then proceeds inferiorly. Compared to the trans-axillary or BABA approaches, both the distance and area of dissection is reduced. The peri-areolar dissection and the dissection across the clavicle during flap elevation are avoided. However, it is limited just to hemithyroidectomy [68].

\section{Robotic-Assisted Neck Dissection for Thyroid Cancer}

Approximately $10-20 \%$ of patients with papillary thyroid cancer can present with palpable lateral lymph node metastasis. A total thyroidectomy and comprehensive lateral neck dissection is the treatment of choice for this group of patients. The minimally invasive or endoscopic central or lateral neck dissection has been proven to be feasible and safe [10, 27, 41, 69]. However, there is limited operating space and that makes the manipulation with endoscopic instruments difficult. With the help of the robotic system, more precise and angulation of manipulation can be performed. Kang et al. [38••] reported the first comparative study comparing robotic and conventional approaches in radical neck dissection for papillary thyroid cancer. In their studies, despite a selection bias towards younger-aged patients, and towards smaller tumors and earlier tumor stages in the robotic group, the complication rates and mean numbers of lymph node retrieved were similar. Operations took longer $(277.4 \pm 43.2$ vs. $218.2 \pm$ $43.8 \mathrm{~min}, p<0.00001$ ), but patients were able to be discharged earlier $(6.0 \pm 2.5$ vs. $8 \pm 5.2$ days, $p<0.008)$ in the robotic group. The postoperative suppressed thyroglobulin level and the rate of abnormal uptake in RAI scans were also comparable to the conventional open approach. Further prospective studies on robotic thyroidectomy with neck dissection are needed to confirm its cosmetic benefit and oncological safety.

Though metastasis to level I, IIb, and Va lymph nodes was not uncommon $(<5-8 \%)$, access to these levels was 
restricted by the trans-axillary or BABA approaches. Kim et al. introduced a new technique called the trans-axillary and retro-auricular approach (TARA). TARA potentially provides a better access and comprehensive neck dissection to these levels [70]. Robotic arms are inserted through retro-auricular and axillary incisions. The level IIb and Va lymph nodes are dissected under direct vision through the retro-auricular incision. Level I lymph nodes are dissected with the robotic arm at the retro-auricular incision. A case series of 7 patients with head and neck squamous cell cancer was recently reported [70].

\section{Selection of Approach and Patient Satisfaction}

Different minimally invasive approaches have been described in the literature. Currently, there is no evidence to suggest that one particular approach is better than others. It appears it is highly variable and dependent on the surgeon's own experience and the patient's preference. Nevertheless, we tried to answer this question by comparing the short-term surgical outcomes, scar appearance and patient satisfaction between MIVAT and the transaxillary approach. In our recent comparison, we found that the transaxillary approach was a technically more challenging procedure and was associated with a longer hospital stay, longer operating time, more immediate pain, and increased overall RLN injury and morbidity compared with MIVAT. The 6-month scar appearance and patient satisfaction were similar between the two procedures [71••].

By operating with a minimal invasive or endoscopic approach, reports suggest a higher patient satisfaction and cosmetic outcome can be achieved [12••, 28]. However, we could not negate the potential publication bias. Recent reports in Europe even criticized the size of the incision in MIVAT as not being associated with better patient satisfaction [72, 73].

\section{Conclusions}

Since the first report of endoscopic subtotal parathyroidectomy in 1996, a variety of endoscopic surgical approaches have been reported. They can be categorized into the cervical/direct approach and the extra-cervical/indirect approach. Each technique or approach has its own benefits and weaknesses. Currently, there is no preferred approach and the choice between different approaches seems to be determined by the surgeon's own experience and the patient's preference. In our experience, the transaxillary approach was a technically more challenging procedure and was associated with longer hospital stay, longer operating time, more immediate pain, and increased overall
RLN injury and morbidity compared with the MIVAT. The 6-month scar appearance and patient satisfaction were similar between the two procedures.

Disclosure No potential conflicts of interest relevant to this article were reported.

\section{References}

Papers of particular interest, published recently, have been highlighted as:

•• Of major importance

1. Gagner M. Endoscopic subtotal parathyroidectomy in patients with primary hyperparathyroidism. Br J Surg. 1996;83(6):875.

2. Slotema ET, Sebag F, Henry JF. What is the evidence for endoscopic thyroidectomy in the management of benign thyroid disease? World J Surg. 2008;32(7):1325-32.

3. Tan CT, Cheah WK, Delbridge L. "Scarless" (in the neck) endoscopic thyroidectomy (SET): an evidence-based review of published techniques. World J Surg. 2008;32(7):1349-57.

4. Miccoli $P$, et al. Minimally invasive surgery for thyroid small nodules: preliminary report. J Endocrinol Invest. 1999;22(11):849-51.

5. Bellantone $\mathrm{R}$ et al. Video-assisted vs conventional thyroid lobectomy: a randomized trial. Arch Surg. 2002;137(3):301-4; discussion 305.

6. El-Labban GM. Minimally invasive video-assisted thyroidectomy versus conventional thyroidectomy: a single-blinded, randomized controlled clinical trial. J Minim Access Surg. 2009;5(4):97-102.

7. Miccoli P, Materazzi G, Berti P. Minimally invasive thyroidectomy in the treatment of well differentiated thyroid cancers: indications and limits. Curr Opin Otolaryngol Head Neck Surg. 2010;18(2):114-8

8. Minuto MN, et al. Minimally invasive video-assisted thyroidectomy: an analysis of results and a revision of indications. Surg Endosc. 2012;26(3):818-22.

9. Spinelli $\mathrm{C}$, et al. Minimally invasive video-assisted thyroidectomy in pediatric patients. J Pediatr Surg. 2008;43(7):1259-61.

10. Lombardi CP, et al. Minimally invasive video-assisted functional lateral neck dissection for metastatic papillary thyroid carcinoma. Am J Surg. 2007;193(1):114-8.

11. Miccoli $\mathrm{P}$, et al. Minimally invasive video-assisted thyroidectomy for benign thyroid disease: an evidence-based review. World J Surg. 2008;32(7):1333-40.

12. $\bullet$ Radford PD, et al. Meta-analysis of minimally invasive videoassisted thyroidectomy. Laryngoscope. 2011;121(8):1675-81. This metanalysis analyzed 5 comparative studies and showed superior result in paincontrol and cosmetic outcome but comparable surgical complication in MIVATcompared to conventional thyroidectomy.

13. Miccoli P. et al. Minimally invasive video-assisted thyroidectomy for papillary carcinoma: a prospective study of its completeness. Surgery. 2002;132(6):1070-3; discussion 1073-4.

14. Miccoli P, et al. Surgical treatment of low- and intermediate-risk papillary thyroid cancer with minimally invasive video-assisted thyroidectomy. J Clin Endocrinol Metab. 2009;94(5):1618-22.

15. Henry JF, et al. Minimally invasive videoscopic parathyroidectomy by lateral approach. Langenbecks Arch Surg. 1999;384(3): 298-301.

16. Gosnell JE, et al. Minimal access thyroid surgery: technique and report of the first 25 cases. ANZ J Surg. 2004;74(5):330-4. 
17. Sywak MS et al. A randomized controlled trial of minimally invasive thyroidectomy using the lateral direct approach versus conventional hemithyroidectomy. Surgery. 2008;144(6):1016-21; discussion 1021-2.

18. Palazzo FF, et al. Safety and feasibility of thyroid lobectomy via a lateral $2.5-\mathrm{cm}$ incision with a cohort comparison of the first 50 cases: evolution of a surgical approach. Langenbecks Arch Surg. 2005;390(3):230-5.

19. Lundgren CI, et al. Minimally invasive thyroid surgery for diagnostic excision of solitary thyroid nodules. Asian J Surg. 2007;30(4):250-4.

20. Shimizu K, Akira S, Tanaka S. Video-assisted neck surgery: endoscopic resection of benign thyroid tumor aiming at scarless surgery on the neck. J Surg Oncol. 1998;69(3):178-80.

21. Ohgami M, et al. Scarless endoscopic thyroidectomy: breast approach for better cosmesis. Surg Laparosc Endosc Percutan Tech. 2000;10(1):1-4.

22. Lee YS, et al. Endoscopic thyroidectomy via a transaxillary approach is a safe procedure in patients with breast augmentation. Surg Innov. 2012. doi:10.1177/1553350612447694.

23. Ikeda Y, et al. Endoscopic neck surgery by the axillary approach. J Am Coll Surg. 2000;191(3):336-40.

24. Chang EH, Lobe TE, Wright SK. Our initial experience of the transaxillary totally endoscopic approach for hemithyroidectomy. Otolaryngol Head Neck Surg. 2009;141(3):335-9.

25. Rao RS, Duncan TD. Endoscopic total thyroidectomy. JSLS. 2009;13(4):522-7.

26. Yoo H, et al. Comparison of surgical outcomes between endoscopic and robotic thyroidectomy. J Surg Oncol. 2012;105(7): $705-8$.

27. Kang SW, et al. Gasless endoscopic thyroidectomy using transaxillary approach; surgical outcome of 581 patients. Endocr J. 2009;56(3):361-9.

28. Ikeda Y, et al. Endoscopic thyroidectomy and parathyroidectomy by the axillary approach. A preliminary report. Surg Endosc. 2002;16(1):92-5.

29. Udomsawaengsup $S$, et al. Endoscopic transaxillary thyroid lobectomy: flexible vs rigid laparoscope. J Med Assoc Thai. 2004;87(Suppl 2):S10-4.

30. Chantawibul S, Lokechareonlarp S, Pokawatana C. Total video endoscopic thyroidectomy by an axillary approach. J Laparoendosc Adv Surg Tech A. 2003;13(5):295-9.

31. Yoon JH, Park CH, Chung WY. Gasless endoscopic thyroidectomy via an axillary approach: experience of 30 cases. Surg Laparosc Endosc Percutan Tech. 2006;16(4):226-31.

32. Jung EJ, et al. Endoscopic thyroidectomy using a gasless axillary approach. J Laparoendosc Adv Surg Tech A. 2007;17(1):21-5.

33. Witzel K. The axillary access in unilateral thyroid resection. Langenbecks Arch Surg. 2007;392(5):617-21.

34. Duncan TD, et al. Endoscopic transaxillary approach to the thyroid gland: our early experience. Surg Endosc. 2007;21(12): 2166-71.

35. Ikeda Y, et al. Are there significant benefits of minimally invasive endoscopic thyroidectomy? World J Surg. 2004;28(11):1075-8.

36. Jeong JJ, et al. Comparative study of endoscopic thyroidectomy versus conventional open thyroidectomy in papillary thyroid microcarcinoma (PTMC) patients. J Surg Oncol. 2009;100(6): 477-80.

37. Chung YS et al. Endoscopic thyroidectomy for thyroid malignancies: comparison with conventional open thyroidectomy. World J Surg. 2007;31(12):2302-6; discussion 2307-8.

38. • Kang SW, et al. A comparative study of the surgical outcomes of robotic and conventional open modified radical neck dissection for papillary thyroid carcinoma with lateral neck node metastasis. Surg Endosc. 2012;26(11):3251-7. doi:10.1007/s00464-012-2333-1. The only available comparative study on robotic neck dissection in patient with thyroid carcinoma with lateral neck lymph node metastasis. It showed similar number of lymph node retrieval and duration of post-operative hospital stay in this "scarless" approach.

39. Lee J, Chung WY. Current status of robotic thyroidectomy and neck dissection using a gasless transaxillary approach. Curr Opin Oncol. 2012;24(1):7-15.

40. Agcaoglu O, et al. Robotic transaxillary central neck dissection: video description of the technique. Surg Laparosc Endosc Percutan Tech. 2012;22(4):e197-8.

41. Koh YW, et al. Endoscopic hemithyroidectomy with prophylactic ipsilateral central neck dissection via an unilateral axillo-breast approach without gas insufflation for unilateral micropapillary thyroid carcinoma: preliminary report. Surg Endosc. 2010;24(1):188-97.

42. Kim WS, et al. Increasing the size limit of benign thyroid lesions resectable by endoscopic thyroidectomy via a unilateral axillobreast approach without gas insufflation. World J Surg. 2011; 35(10):2203-11.

43. Lee D, Nam Y, Sung K. Single-incision endoscopic thyroidectomy by the axillary approach. J Laparoendosc Adv Surg Tech A. 2010;20(10):839-42.

44. Fan Y, Wu SD, Kong J. Single-port access transaxillary totally endoscopic thyroidectomy: a new approach for minimally invasive thyroid operation. J Laparoendosc Adv Surg Tech A. 2011;21(3):243-7.

45. Shimazu K, et al. Endoscopic thyroid surgery through the axillobilateral-breast approach. Surg Laparosc Endosc Percutan Tech. 2003;13(3):196-201.

46. Choe JH, et al. Endoscopic thyroidectomy using a new bilateral axillo-breast approach. World J Surg. 2007;31(3):601-6.

47. • Choi JY, et al. Endoscopic thyroidectomy via bilateral axillobreast approach (BABA): review of 512 cases in a single institute. Surg Endosc. 2012;26(4):948-55. The largest series reported the single outcome of endoscopic thyroidectomy with BABA approach.

48. Duh QY. Presidential address: minimally invasive endocrine surgery-standard of treatment or hype? Surgery. 2003;134(6): 849-57.

49. Kim SJ, et al. Recovery of sensation in the anterior chest area after bilateral axillo-breast approach endoscopic/robotic thyroidectomy. Surg Laparosc Endosc Percutan Tech. 2011;21(5):366-71.

50. Lee KE, et al. Postauricular and axillary approach endoscopic neck surgery: a new technique. World J Surg. 2009;33(4):767-72.

51. Walvekar RR, et al. Retro-auricular video-assisted "gasless" thyroidectomy: feasibility study in human cadavers. Surg Endosc. 2010;24(11):2895-9.

52. Benhidjeb $\mathrm{T}$, et al. Natural orifice surgery on thyroid gland: totally transoral video-assisted thyroidectomy (TOVAT): report of first experimental results of a new surgical method. Surg Endosc. 2009;23(5):1119-20.

53. Karakas E, et al. Transoral thyroid and parathyroid surgery-development of a new transoral technique. Surgery. 2011;150(1):108-15.

54. Miccoli P, Materazzi G, Berti P. Natural orifice surgery on the thyroid gland using totally transoral video-assisted thyroidectomy: report of the first experimental results for a new surgical method: are we going in the right direction? Surg Endosc. 2010;24(4):957-8; author reply 959-60.

55. Dionigi G, Rovera F, Boni L. Commentary on transoral access for endoscopic thyroid resection: Witzel K, von Rahden BH, Kaminski C, Stein HJ (2008) Transoral access for endoscopic thyroid resection. Surg Endosc 22(8):1871-1875. Surg Endosc. 2009;23(2):454-5; discussion 456.

56. Kang SW, et al. Robot-assisted endoscopic thyroidectomy for thyroid malignancies using a gasless transaxillary approach. J Am Coll Surg. 2009;209(2):e1-7.

57. Lee J, et al. Comparison of endoscopic and robotic thyroidectomy. Ann Surg Oncol. 2011;18(5):1439-46. 
58. Kuppersmith RB, Holsinger FC. Robotic thyroid surgery: an initial experience with North American patients. Laryngoscope. 2011;121(3):521-6.

59. Lang BH, Chow MP. A comparison of surgical outcomes between endoscopic and robotically assisted thyroidectomy: the authors' initial experience. Surg Endosc. 2011;25(5):1617-23.

60 . Lee J, et al. Multicenter study of robotic thyroidectomy: shortterm postoperative outcomes and surgeon ergonomic considerations. Ann Surg Oncol. 2011;18(9):2538-47.

61. $\bullet$ Ryu HR, et al. Feasibility and safety of a new robotic thyroidectomy through a gasless, transaxillary single-incision approach. J Am Coll Surg. 2010;211(3):e13-9. The study introduced the single-incision transaxillary approach for robotic thyroidectomy. The study proved it is safe and technically feasible with comparable outcome with traditional transaxillary approach.

62. Lee KE, Rao J, Youn YK. Endoscopic thyroidectomy with the da Vinci robot system using the bilateral axillary breast approach (BABA) technique: our initial experience. Surg Laparosc Endosc Percutan Tech. 2009;19(3):e71-5.

63. $\bullet$ Lee S, et al. Excellence in robotic thyroid surgery: a comparative study of robot-assisted versus conventional endoscopic thyroidectomy in papillary thyroid microcarcinoma patients. Ann Surg. 2011;253(6):1060-6. This comparative study showed the superiority of robotic thyroidectomy in terms of increased $L N$ retrieval and shorter operating time.

64. Lang BH, Chow MP, Wong KP. Endoscopic vs robotic thyroidectomy: which is better? Ann Surg Oncol. 2011;18(Suppl 3):S251.

65. • Lee J, et al. The learning curve for robotic thyroidectomy: a multicenter study. Ann Surg Oncol. 2011;18(1):226-32. This study compared the learning curve of robotic and endoscopic transaxillary thyroidectomy.

66. Broome JT, Pomeroy S, Solorzano CC. Expense of robotic thyroidectomy: a cost analysis at a single institution. Arch Surg. 2012. doi:10.1001/archsurg.2012.1870.

67. Terris DJ, Singer MC. Robotic facelift thyroidectomy: facilitating remote access surgery. Head Neck. 2012;34(5):746-7.

68. Terris DJ, Singer MC. Qualitative and quantitative differences between 2 robotic thyroidectomy techniques. Otolaryngol Head Neck Surg. 2012;147(1):20-5.

69. Miccoli P, et al. Video-assisted central compartment lymphadenectomy in a patient with a positive RET oncogene: initial experience. Surg Endosc. 2007;21(1):120-3.

70. Kim WS, et al. Feasibility of robot-assisted neck dissections via a transaxillary and retroauricular ("TARA") approach in head and neck cancer: preliminary results. Ann Surg Oncol. 2012;19(3): 1009-17.

71. $\bullet$ Lang BH, Wong KP. A comparison of surgical morbidity and scar appearance between gasless, transaxillary endoscopic thyroidectomy (GTET) and minimally invasive video-assisted thyroidectomy (VAT). Ann Surg Oncol. 2012. doi:10.1245/s10434-012-2613-y.A study compared cervical (MIVAT) and extra-cervical (transaxillary thyroidectomy) approaches.

72. Bokor $\mathrm{T}$, et al. Cosmesis and body image after minimally invasive or open thyroid surgery. World J Surg. 2012;36(6):1279-85.

73. Linos, D., et al., Scar perceptions after thyroid and parathyroid surgery: Comparison of minimal and conventional approaches. Surgery. 2012. doi:10.1016/j.surg.2012.08.008. 